\title{
Nimesulide induced toxic epidermal necrolysis: a rare case report
}

\author{
Vineet Kumar*, Manju Gari, Kishor Chakraborty, Ravi Ranjan, Anshuman Chandra, \\ Kavita Kumari
}

Department of Pharmacology and Therapeutics, Rajendra Institute of Medical Sciences, Ranchi, Jharkhand, India

Received: 06 October 2017 Accepted: 28 October 2017

*Correspondence to:

Dr. Vineet kumar,

Email: kumarvineetcmc@ gmail.com

Copyright: (C) the author(s), publisher and licensee Medip Academy. This is an openaccess article distributed under the terms of the Creative Commons Attribution NonCommercial License, which permits unrestricted noncommercial use, distribution, and reproduction in any medium, provided the original work is properly cited.

\begin{abstract}
Adverse drug reactions to the prescribed medicines are the major obstacles in continuation of drug treatment. Nimesulide, a selective cyclo-oxygenase (COX2) inhibitor was first launched in Italy in 1985 and subsequently marketed in more than 50 countries including India. Due to its better and faster antipyretic action, it has gained popularity among physicians and paediatricians. Here, we report a case of 60 years old male patient who developed toxic epidermal necrolysis (TEN) following ingestion of tablet nimesulide. The patient was managed with parenteral corticosteroids, antibiotics, emollients, anti-fungal and supportive care. This case highlights the importance of nimesulide and other NSAIDs as possible cause of TEN. Nimesulide has never been approved in countries like USA, Canada, Britain, New Zealand, Australia. But in India it is available as over the counter drug and is used for various indications like fever, myalgia, arthralgia. Therefore, the drugs which are banned outside India should be used with caution and medical practitioners should report all the adverse drug reactions to such drugs.
\end{abstract}

Keywor ds: Nimesulide, Steven Johnson syndrome, Toxic epidermal necrolys is

\section{INTRODUCTION}

Adverse drug reactions to the prescribed medicines are the major obstacles in continuation of drug treatment. StevensJohnson syndrome (SJS) and toxic epidermal necrolys is (TEN), are severe idiosyncratic reactions characterized by fever and mucocutaneous lesions leading to necrosis and sloughing of the epidermis.

Drugs are most commonly implicated for causing 77-95\% of cases. ${ }^{1,2}$ Among the drugs, implicated more often are allopurinol, antibiotics, anticonvulsants, and nonsteroid anti-inflammatories. ${ }^{3}$ In addition to medications, conditions such as malignancies, systemic lupus erythematosus, viral infections, exposure to ultraviolet rays may trigger SJS/TEN.

Nimesulide, a selective cyclo-oxygenase (COX-2) inhibitor was first launched in Italy in 1985 and subsequently marketed in more than 50 countries including India. ${ }^{4,5}$ Nimesulide is an approved analgesic, indicated in the symptomatic treatment of osteoarthritis in adults and for primary dysmenorrhoea in adolescents above 12 years. Due to its better and faster antipyretic action, it gained popularity among physicians. In 2003, following worldwide reports of increased incidence of hepatopathy in children, some countries banned the use of nimesulide. From 10 March 2011 onwards Nimesulide 
formulations for human use in children below 12 years of age has been banned in India. ${ }^{6}$ However adult formulations were not banned and nimesulide still remains one of the most easily available, over the counter (OTC) drug in India, being used for adults as well as children, a great problem for the safety of people's health.

\section{CASE REPORT}

A $60 \mathrm{yr}$ old male presented to skin department of our hos pital with complaints of fever for four days, as sociated with chills and rigors for last 1 day with no diurnal variation and rashes (hyperpigmented erythematous papules) over whole body with burning sensation since last 4 days. Rashes initially started over face (along with a fluid filled vesicle over the cheek) which spread to the neck, chest, back, and abdomen, genitalia and upper and lower legs within 24 hours.

There was also history of swelling of lips with multiple oral ulcers and decreased mouth opening. After detailed inquiry, patient gave a history of ingestion of tablet Nimesulide prescribed by a general practitioner for fever 4 days back. The rash and the other complaints started after ingestion of tablet Nimesulide within few hours. There was no history of other drug intake or past history of allergy to any drug. He then stopped taking nimesulide and took paracetamol instead for fever and then came to get treatment in a local hospital of Ranchi and from there he was referred to RIMS, Ranchi.

On examination, patient was ill looking, vitals were stable except tachycardia (pulse-110/min). Erythematous vesicular rash was present over face, neck, chest, abdomen, upper and lower limbs including genitalia with crusting (Figure 1 to Figure 5).

Macular rashes were present over palms and soles too. Ocular examination revealed congestion of both conjunctiva. Oral examination revealed oedematous lips, multiple oral ulcers with decreased mouth opening. Other systemic examinations were within normal limits.

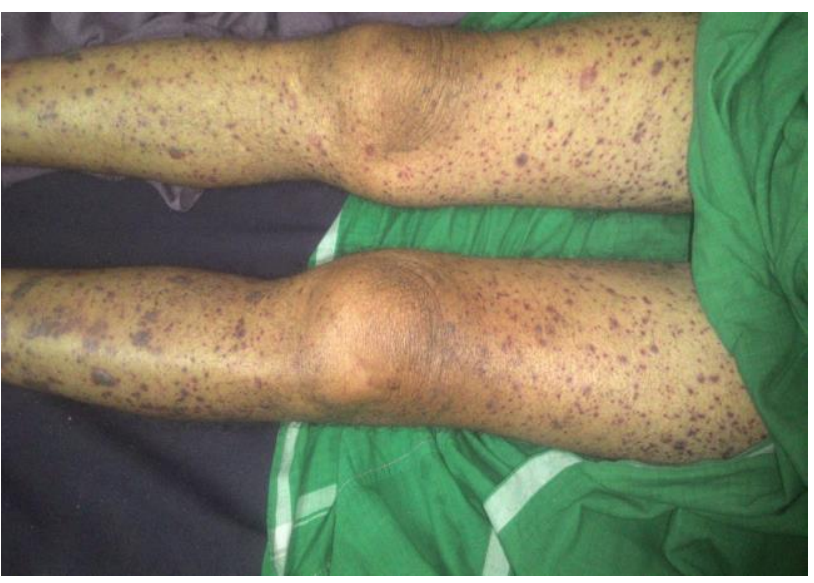

Figure 1: Frythematous vesicular rashes over both lower limbs.
Haematological and biochemical investigations were sent, which revealed slight derangement in the Liver Function Test with SGPT 77 IU/L, SGOT of 83 IU/L and urea 86 $\mathrm{mg} / \mathrm{dl}$ and creatinine $1.6 \mathrm{mg} / \mathrm{dl}$. Bilirubin levels, Chest XRay, Urine Routine and Microscopic examination all were within normal limits. HIV, HbsAg/anti HCV were negative.

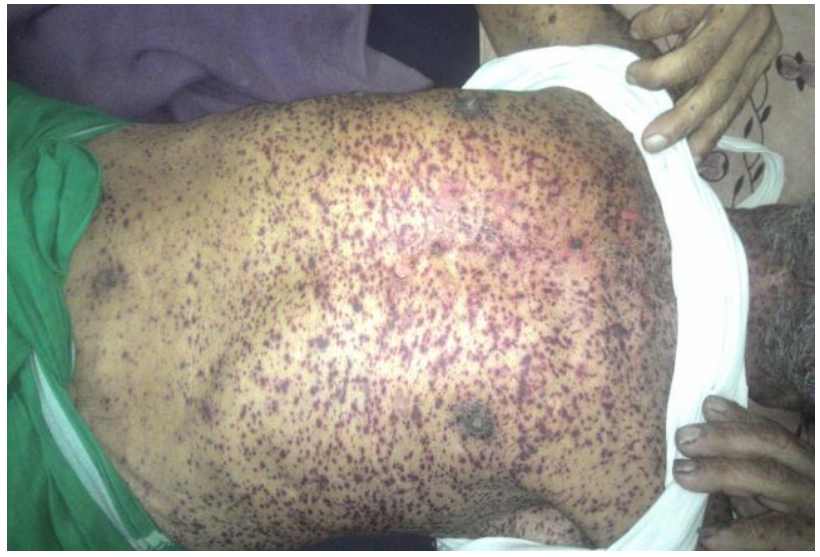

Figure 2: Erythematous vesicular rash over chest and abdomen of patient.

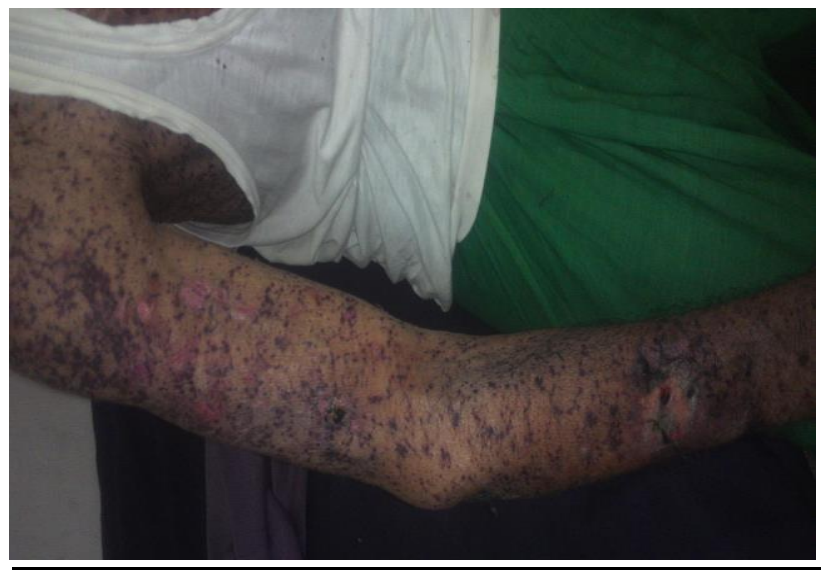

Figure 3: Ruptured vesicles and crusted rash and ulcers over arm and forearm in healing stage.

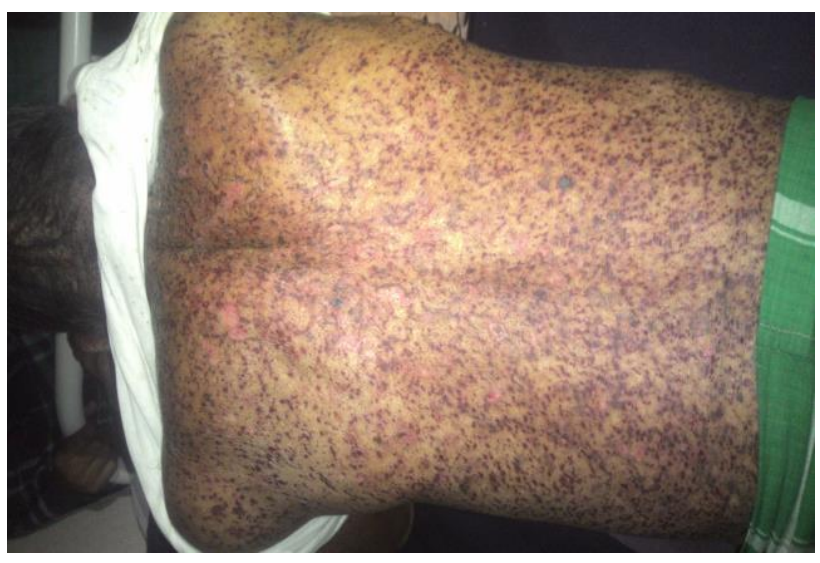

Figure 4: Erythematous vesicular rash over back of patient. 


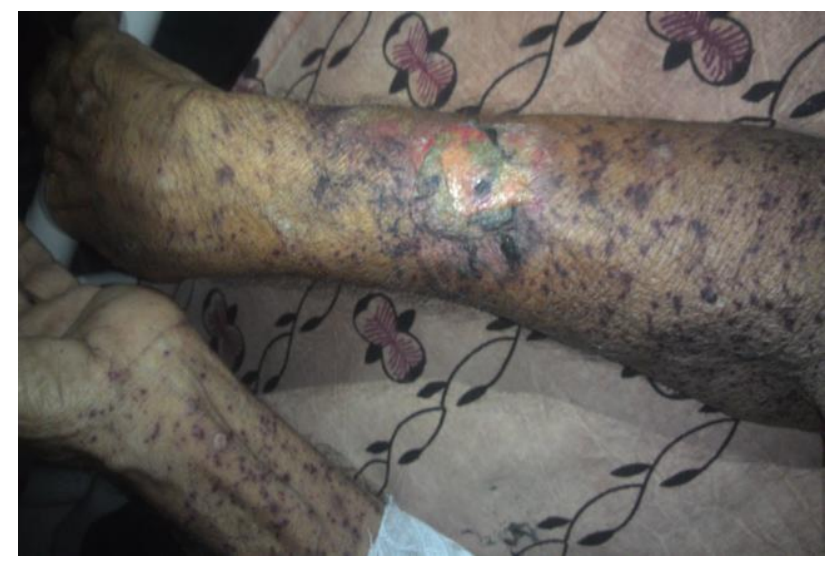

Figure 5: A large ulcer over back of forearm (skin peeling).

With the history, clinical examination and investigatory findings diagnosis of Nimesulide induced Toxic epidermal necrolysis was made and the patient managed with parenteral steroids, third generation cephalosporin, local application of steroid intraorally, local anaesthetic gel for oral lesions followed by mouth paint. Antiseptic/antibiotic eye drops were also used.

Following scales are applied for the assessment of the event:

- WHO-UMC scale for causality assessment'Probable'.

- Naranjo’s scale- Probable.

\section{DISCUSSION}

Stevens Johnson Syndrome and Toxic Epidermal Necrolysis, considered as two ends of the spectrum of severe epidermolytic adverse cutaneous drug reactions, differ only in their extent of skin detachment. ${ }^{7}$ Depending upon the body surface area (BSA) involved, three entities are recognized.

- SJS: A minor form of TEN, with $<10 \%$ BSA involvement

- Overlapping SJS/TEN: Ten to thirty percent of the BSA

- TEN: More than $30 \%$ of the BSA involved.

Medications are the leading trigger of SJS and TEN in adults. Infections are responsible for a relatively higher percentage of cases in children. In addition to medications, conditions such as malignancies, systemic lupus erythematosus, viral infections, exposure to ultraviolet rays may trigger SJS/TEN.

Among the drugs, more often implicated are allopurinol, antibiotics, anticonvulsants, and nonsteroidal anti-inflammatories. Newer drugs that have been associated with SJS and TEN include nevirapine, lamotrigine, sertraline, pantoprazole, and tramadol. ${ }^{8}$
Even though rare, (two cases per million population per year) SJS and TEN have a significant impact on public health, because of its high mortality, disability, cost of treatment, and reluctance of survivors to the use of any medications subsequently.

This case is being reported, taking into consideration the rare association of nimesulide induced TEN. The WHO ADR database (VIGIFLOW), has several reports of nimesulide- induced hepatotoxicity and milder skin reactions and SJS but till date there are only a very few reported cases of TEN following nimesulide therapy.

\section{CONCLUSION}

Nimesulide is readily available as an over the counter drug (OTC) in India for various indications such as fever, myalgia, osteoarthritis etc. Nimesulide has never been approved in countries like USA, Canada, Australia. Therefore, in India practitioners should report all the adverse drug reactions seen with the drugs like Nimesulide which are banned outside India and should use it carefully and only when other alternatives are not available. Whenever nimesulide is prescribed it should be carefully monitored for any adverse effects, known or unknown.

\section{ACKNOWLEDGEMENTS}

Authors would like to thank Pharmacovigilance Programme of India running under Indian Pharmacopoeia Commission (IPC) Ministry of health and family welfare for providing technical logistical support to the centre for ADR reporting.

\section{Funding: No funding sources}

Conflict of interest: None declared

Ethical approval: Not required

\section{REFERENCES}

1. Roujeau JC, Stern RS. Severe adverse cutaneous reactions to drugs. New England Journal of Medicine. 1994;331(19): 1272-85.

2. Sehgal VN, Srivastava G. Toxic epidermal necrolys is (TEN) Lyell's syndrome. Journal of dermatological treatment. 2005;16(5-6):278-86.

3. Letko E, Papaliodis DN, Papaliodis GN, Daoud YJ, Ahmed AR, Foster CS. Stevens-Johnson syndrome and toxic epidermal necrolysis: a review of the literature. Annals of Allergy, Asthma \& Immunology . 2005;94(4):419-36.

4. Burke A, Smyth E, Fitzgerald GA. Analgesicantipyretic agents: Pharmacotherapy of gout. In: Brunton LB, Lazo JS, Parker KL, eds.Goodman \& Gilman's The Pharmacological Basis of Therapeutics. 11th ed. New York, NY: McGraw-Hill; 2005:706.

5. Conforti A, Leone R, Moretti U, Mozzo F, Velo G. Adverse drug reactions related to the use of NSAIDs with a focus on nimesulide. Drug safety. 2001;24(14):1081-90. 
6. CDSCO website-wide gazette notification GSR 82(E) dated 10.02.2011

Available

at: http://cdsco.nic.in/writereaddata/GSR_82_E.pdf.

7. Harr T, French LE. Toxic epidermal necrolysis and Stevens-Johnson syndrome. Orphanet $\mathrm{J}$ of Rare Diseases. 2010;5(1):39.

8. Mockenhaupt M, Viboud C, Dunant A, Naldi L, Halevy S, Bavinck JN, et al. Stevens-Johnson syndrome and toxic epidermal necrolysis: assessment of medication risks with emphasis on recently marketed drugs. The EuroSCAR-study. Journal of Investigative Dermatology. 2008 Jan 31;128(1):35- 44.

Cite this article as: Kumar V, Gari M, Chakraborty K, Ranjan R, Chandra A, Kumari K Nimesulide induced toxic epidermal necrolysis: a rare case report. Int J Basic Clin Pharmacol 2017;6:2939-42. 